\title{
Clinical applications of direct antiglobulin test
}

\author{
Jeong-Shi Lin ${ }^{1,2,3 *}$ \\ ${ }^{1}$ Division of Transfusion Medicine, Department of Medicine, Taipei Veterans General Hospital, Taipei, Taiwan \\ ${ }^{2}$ Division of Hematology, Department of Medicine, Taipei Veterans General Hospital, Taipei, Taiwan \\ ${ }^{3}$ National Yang-Ming University School of Medicine, Taipei, Taiwan
}

\begin{abstract}
The direct antiglobulin test (DAT) is used to detect immunoglobulin and/or complement on the surface of red blood cells (RBCs). The DAT is valuable in the investigation of autoimmune hemolytic anemia, drug-induced immune hemolysis, hemolytic disease of newborn, hemolytic transfusion reactions, and passenger lymphocyte syndrome. There are several limitations of DAT, such as sensitivity, false positive and false negative. The patient's clinical history, diagnoses, and other laboratory test results should also take into consideration for DAT interpretation.
\end{abstract}

\section{Introduction}

The direct antiglobulin test (DAT), also known as ' direct Coombs' test', was found more widespread notoriety after been described in 1945 by Cambridge immunologist Robin Coombs. The DAT is used to detect immunoglobulin, complement, or both on the surface of red blood cells (RBCs). The indirect antiglobulin test (IAT) is used to detect red cell antibodies in patient serum. In certain diseases or conditions, their RBCs are coated with immunoglobulin. Complement proteins may subsequently bind to the bound antibodies.

There are many clinical conditions with a positive DAT. A positive DAT does not mean decreased RBC lifespan. The incidence of a positive DAT in normal blood donors is in the range of 1:1000 to 1:36,000, and is higher in older donors than in younger ones $[1,2]$.

\section{Limitations of DAT}

\section{The sensitivity of the direct antiglobulin test}

The DAT are usually performed by conventional tube technique, gel microcolumn DAT, affinity microcolumn DATs. There are several "enhanced" DATs (e.g. $4^{\circ} \mathrm{C}$ Low-ionic-strength saline wash or polybrene) that can be performed [3].The immunoradiometric assay (IRMA) [4], the complement fixation antibody consumption test [5] and the enzyme-liked immunoassay test (ELAT) [6], as well as the enzyme-linked immunosorbent assay (ELISA) [7] are representative methods to quantitatively detect RBC-IgG. Flow cytometric DAT [8] and the gel microcolumn DAT [9] are semiquantitative methods. Flow cytometry is a precise, reliable, and sensitive method of detecting RBCbound autoantibodies [10]. Flow cytometric DAT is a complementary test for diagnosing AIHA [8].

Most DATs are routinely performed by conventional tube technique with a polyspecific reagent capable of detecting both IgG and C3d. The concentration of IgG antibody on the RBCs that is required for a positive DAT is quite variable. Hughes-Jones et al. have observed minimally detectable agglutination by antiglobulin test with IgG concentrations ranging from 100 to 500 molecules per RBC [11]. The conventional tube DAT has the disadvantage of low sensitivity.
Gel microcolumn DATs were more sensitive than tube agglutination and affinity microcolumn DATs [12]. Gel microcolumn DAT is a better alternative to conventional tube DAT for detecting red cell bound antibodies in various clinical conditions [13]. The sensitive gel technology has enabled the hematologist not only to diagnose some AIHA patients with negative DAT, but also to characterize red cell bound autoantibodies with regard to their class, subclass and titer in a rapid and simplified way [14].

Fabijanska-Mitek et al. [15] evaluated a gel-DAT and ELAT in the laboratory diagnosis of autoimmune hemolytic anaemia (AIHA). They studied 106 samples collected from 65 patients with clinical symptoms of AIHA. He found that the ELAT was positive in 100 samples (94\%), 87 samples for tube-DAT (82\%); and the gel-DAT was therefore not fully specific and detected IgG on red cells of patients with hypergammaglobulinaemia.

The interpretation of the significance of a direct antiglobulin test result should take into consideration the patient's clinical history (drug, pregnancy, transfusion and transplantation history), diagnoses, and other laboratory test results (including evidence of hemolysis).

\section{Relationship of antibody concentration and IgG subtype to rate of hemolysis}

The rate of RBC destruction is generally related to the concentration of RBC-bound antibody [16]. But there was considerable overlap in the respective ranges of percent fluorescence of RBCs from patients with and without immune hemolytic anemia (IHA). It was not possible to define a clear quantitative threshold differentiating patients with IHA from those without [17].

${ }^{\star}$ Correspondence to: Jeong-Shi Lin, Division of Transfusion Medicine, Department of Medicine, Taipei Veterans General Hospital, Shih-Pai Road, Taipei, Taiwan, Tel: 886-2-2875-7623; Fax: +886-2-2857-7695; E-mail: jslin@vghtpe.gov.tw

Key words: direct antiglobulin test, autoimmune hemolytic anemia, transfusion

Received: September 03, 2018; Accepted: September 14, 2018; Published: September 17, 2018 
Fabijanska-Mitek et al. [18] found that laboratory signs of hemolysis were present in $65.7 \%$ of blood samples with a small amount of red cell-bound autoantibody ( $<200 \mathrm{IgG}$ molecules/red blood cell) and in $70.4 \%$ of blood samples with moderately coated red blood cells (2001000 molecules/red blood cell). Hemolysis was demonstrated in $87.9 \%$ samples with > 1000 IgG molecules/red blood cell. The numbers of red blood cell-bound autoantibody molecules were small in those patients who were recovering from AIHA, whereas strongly sensitized red blood cells were found at the beginning of the disease. The results confirmed the relationship between the number of IgG molecules on $\mathrm{RBC}$ and the severity of AIHA.

However AIHA severity might be also dependent on some qualitative features of autoantibodies, such as the variety of subclasses of IgG, presence of IgG3 on red blood cells [19]. Singh et al. [20] observed a statistically significant $(\mathrm{p}<0.005)$ association of hemolysis with increasing anti-IgG titer, and statistically significant $(\mathrm{p}<0.005)$ association of subclass of IgG (IgG1, IgG3) coating the red blood cells with intravascular hemolysis. Constantoulakis et al. demonstrated that the rate of hemolysis depends more on the characteristics of the individual's antibody than on the antibody concentration per RBC [21]. There is a synergistic effect of the red blood cell-bound IgG and complement in predicting hemolysis [8].

\section{Causes of false positive or false negative DAT}

DAT can be positive in patients without AIHA. Reasons for a false positive reaction could be the following: (1) improper sample (clotted cells), (2) spontaneous RBC agglutination, (3) elevation of serum immunoglobulin [22,23], (4) administration of intravenous immune globulin [24], (5) elevated serum globulin and blood urea nitrogen levels [25], (6) over centrifugation [26]. There is a significant correlation between a positive DAT result and serum IgG concentrations, and that the higher the elevated serum $\operatorname{IgG}$, the more frequently the positive DAT result is observed [27].

Causes of false negative DAT includes: (1) improper cell washing, (2) delay in adding antiglobulin reagent after the washing step, (3) inactive, or forgotten, antiglobulin reagent, (4) improper specimen agitation at the time of result interpretation [26].

\section{Clinical Applications of DAT}

\section{Diagnosis and classification of autoimmune hemolytic anemia}

AIHA is caused by autoantibodies against patients' own RBCs leading to hemolytic anemia. The key findings that suggest hemolytic anemia are increase in the reticulocyte count, increased serum lactate dehydrogenase (LDH) and indirect bilirubin, decreased serum haptoglobin, and spherocytes on the peripheral blood smear. The diagnosis of AIHA is usually based on the presence of hemolytic anemia and serologic evidence of anti-RBC autoantibodies by the DAT, which can be performed with various methods with different sensitivity [28]. AIHA can be classified as warm, cold [cold agglutinin disease (CAD)] or mixed, and paroxysmal cold hemoglobinuria (PCH), depending on the thermal range of the autoantibody [28].

It is worth recommending to perform the test with monospecific antisera and to determine the presence of IgG and/or complement on red blood cells (RBCs) [29]. In AIHA, three patterns of reactivity may be found on a direct antiglobulin test: IgG alone, complement alone, or both.
The ability of the anti-erythrocyte antibody to bind to the erythrocyte antigen at specific temperatures is fundamental to the diagnosis in terms of whether it is designated as warm (reacts maximally at $37^{\circ} \mathrm{C}$ ) or cold (reacts maximally at $4^{\circ} \mathrm{C}$ ) AIHA. The pathologic and clinical features of AIHA relate to the autoantibody class, thermal amplitude, and their efficiency in activating complement.

Warm AIHA is generally IgG dependent but can also (rarely) be immunoglobulin $\mathrm{M}$ (IgM) or immunoglobulin A (IgA) dependent, or there could also be more than 1 immunoglobulin class present simultaneously (eg, IgM/C3 together with IgG on the RBC membrane) [30].

The presence of an IHA with a DAT result that is negative for IgG and positive for $\mathrm{C} 3$ should prompt the consideration for a cold AIHA. The category of cold hemolysins includes 2 distinct disease entities: cold agglutinin syndrome and paroxysmal cold hemoglobinuria (PCH), either of which should demonstrate a DAT positive only with C3 antisera [30]. Cold agglutinin syndrome antibodies tend to be IgM with specificity for $\mathrm{I} / \mathrm{i}$ class of antigens, or much less commonly, an IgG or IgA with specificity for Pr antigens [31]. PCH is caused by a biphasic hemolysin referred to as the Donath-Landsteiner antibody, which most often has anti-P specificity [31]. The antibody is a cold-reacting IgG that reacts with RBCs in the periphery cold area. The Donath-Landsteiner antibody is an IgG class antibody that binds at low temperatures, where it fixes complement to the RBCs, then the cells are hemolyzed at warmer temperatures owing to the opsonization with complement.

AIHA can also be categorized into idiopathic and secondary with underlying infectious, malignancies, autoimmune disorders, and druginduced $[32,33]$. Secondary AIHA may be treated in a way similar to primary AIHA, by immunosuppressants or by treatment of the underlying disease [33]. There is evidence of a significantly increased risk of cancer for blood donor with positive DAT, especially hematologic malignancies [34]

\section{DAT-negative AIHA}

Between $2 \%$ and $10 \%$ of all AIHA patients are DAT negative [35]. DAT-negative AIHA is characterized by laboratory evidence of in vivo hemolysis, together with a negative DAT performed by conventional tube method in AIHA patients.

The most common causes of the absence of a positive DAT in AIHA cases are: RBC bound IgG below the detection threshold of the DAT, low affinity IgGs that are removed by preparatory washes, and red cell sensitization by IgA alone, or rarely (monomeric) IgM alone, but not accompanied by complement fixation, and thus not detectable by a routine antiglobulin reagent that contains anti-IgG and anti-C3 [36]. A diagnostic algorithm for DAT-negative AIHA has not yet been established. Kamesaki and Kajii [37] report a detailed laboratory analysis of patients with DAT-negative AIHA and found that the estimated relative fractions of patients with DAT-negative AIHA resulting from RBC-bound IgA or IgM, low-affinity IgG autoantibodies, and RBCbound IgG autoantibodies under the threshold level of positive DAT were approximately 5,15 , and $80 \%$, respectively.

To achieve greater sensitivity, alternative DAT methods have been developed, such as the micro-column (gel), solid-phase, polybrene, and flow cytometry methods, as well as enzyme-linked antiglobulin, immunoradiometric, and mitogen-stimulated tests [38]. There are many other DAT methods, and it is a challenge to choose which combination of methods to use. Moreover, we should keep in mind that these tests for DAT-negative AIHA have a low predictive value, and 
thus the results must be interpreted based on the clinical status of the patients [39]. Many clinicians clinically diagnosed DAT-negative AIHA by the presence of hemolysis, denial of other hemolytic diseases, and responsiveness to steroid treatments.

DAT positivity needed a certain number of antibody molecules sensitizing red blood cells, therefore AIHA with a lower quantity of autoantibodies may present with negative DAT [40]. It is postulated that the properties of the antibody in conjunction with the sensitivity of the reticuloendothelial system for antibody-coated cells account for hemolytic anemia occurring with such low concentrations of antibody [41].

\section{Drug-induced immune hemolytic anemia}

More than 150 drugs have been implicated in causing druginduced immune hemolytic anemia. It can be due to drug-independent auto-antibodies (methyldopa, procainamide, ibuprofen, diclofenac, fludarabine, cladribine), and drug-dependent ("hapen type" or "immune complex type") antibodies (ceftriaxone, cefotetan, penicillin, piperacillin, $\beta$-lactamase inhibitors, and other antibiotics) $[28,42]$.

In drug-independent IHA, the drug may alter antigens on the red cell, resulting in the production of antibodies that cross-react with the unaltered antigen. Such antibodies do not need drug to be present to obtain in vitro reactions. The prime example is that induced by methyldopa [43]. DAT is positive with anti-IgG antisera and usually negative with anti-C3 antisera.

In drug-dependent IHA, the drug may associate with structures on the red cell and thus be part of the antigen in a haptenic reaction. The DAT was positive, and an immune reaction could be demonstrated in vitro in which the drug was a necessary part. Two syndromes result: one in which the drug is firmly bound to the membrane (penicillin type) [44], and one in which the drug is only loosely bound to the membrane glycoprotein (the immune complex type). An example of the immune complex type is AIHA caused by the antibiotic ceftriaxone. All of the affected patients had red cells reactive with anti-C $3 ; 47$ percent of those tested in the authors' lab were reactive with anti-IgG, 22 percent with anti-IgM, and 6 percent with anti-IgA [45]. Drug-dependent antibodies are investigated by testing drug-treated RBCs or by testing RBCs in the presence of a solution of drug [46].

\section{Hemolytic disease of the newborn}

During pregnancy, red blood cells from the fetus can cross into the mother's blood through the placenta. Hemolytic disease of the newborn occurs when the mother's alloantibodies bind paternally inherited antigens present on fetal but absent on maternal RBCs, resulting in a positive DAT and hemolysis. Most cases of hemolytic disease of the newborn (HDN) are caused by alloimmunization to antigens in Rh blood group. However, there are still many other blood group incompatibilities, for example, antibodies against the Kell, Duffy, Kidd, and the MNS blood group system, that may be the cause of HDN. $\mathrm{HDN}$ can also be caused by an incompatibility of the $\mathrm{ABO}$ blood group. It arises when a mother with blood type $O$ has a fetus with a different blood type (type A, B, or AB). High maternal IgG anti-A or -B titres are consistent with an increased risk of HDN [47]. Blood tests done on the newborn baby has positive DAT. Blood tests done on the mother has positive IAT. The use of routine antenatal anti-D prophylaxis has sharply decreased the incidence of and mortality from HDN due to $\mathrm{RhD}$ allosensitization. The ability to identify pregnancies/fetuses at risk of HDN has significantly improved due to paternal molecular RHD zygosity testing, and non-invasive fetal molecular diagnostics for detecting putative antigen(s) (notably $\mathrm{RhD}$ ) in fetuses utilizing cell-free fetal DNA in maternal plasma [48].

\section{Investigation of hemolytic transfusion reactions}

After transfusion, the patient's developing alloantibodies coat transfused RBCs, resulting in a positive DAT result. A Delayed serologic transfusion reactions (DSTRs) was defined by the posttransfusion finding of a positive DAT and a newly developed alloantibody specificity without hemolysis. A delayed hemolytic transfusion reactions (DHTR) was defined as a DSTR case that showed clinical and/or laboratory evidence of hemolysis [49]. They can be caused by irregular alloantibodies against a lot of RBC antigens, most commonly of the Rhesus, Kidd, Duffy, Kell, and MNSs system. DHTR should always be in the differential diagnosis whenever a patient presents with decreasing hemoglobin approximately 5-10 days following a transfusion of RBC.

\section{Passenger lymphocyte syndrome}

The passenger lymphocyte syndrome (PLS) occurs when donor lymphocytes transferred with the transplanted organ produce antibodies toward host relevant RBC antigens. It results in positive DAT and hemolysis. Passenger lymphocyte mediated hemolysis is frequent in minor mismatched liver and kidney transplantation [50]. Risks for PLS include highly lymphoid grafts, past sensitization of the donor against relevant RBC antigens, and donor lymphocyte escape of host immune clearance [51].

\section{No use of routine DAT during pretransfusion testing}

The DAT had a low predictive value when used to detect the early manifestations of an immune response to recently transfused red cells [52]. Due to a low frequency of positive DAT during pretransfusion testing, its cast and the fact that patients had no clinical signs of immune hemolysis, we advocate no use of a routine DAT during pretransfusion testing [53]. Eluate testing should be restricted to cases in which immune hemolysis is suspected clinically [54].

\section{Transfusion for AIHA patients}

The difficulties with $\mathrm{ABO}$ and Rh typing and cross matching tests are common in AIHA samples. The autoantibody in the patient's serum frequently reacts with all normal red blood cells. It may be almost impossible to find a fully matched unit to transfuse these patients. Communication between clinicians and laboratory personnel are important to review the urgency of transfusion and the compatibility test methods used to select the optimal unit of red blood cells for transfusion [55]. Specialized techniques such as elution, alloadsorption or autoadsorption should be established in all transfusion services. [14] The end goal is to identify clinically significant alloantibodies in order to provide antigen negative, compatible red blood cells, which reduces the risk of transfusion related reactions [56].

It is essential to exclude these autoantibodies because they can also mask the detection of alloantibodies. For patients with warm AIHA, the most effective compatibility testing rely on autoadsorption techniques to remove the autoantibody and to allow detection of clinically significant alloantibodies. Moreover, if the patient has already received transfusions in the past, the most suitable procedure will then consist in adsorption using allogeneic RBCs of different known phenotypes.

The determination of the most complete phenotype (including $\mathrm{Rh}$, Kell, Duffy, Kidd, and MNS system antigens) coupled with transfusion with antigen-matched donor units has been proposed as an alternative method to the adsorption techniques [57]. RBC genotyping techniques 
for patients with AIHA allow selecting antigen-matched units without adsorption procedures [58].

For patients with cold agglutinin disease, the blood should be transfused slowly through a blood-warmer and patient should be kept in warm condition to avoid in-vivo hemolysis due to high titer of cold agglutinin.

\section{Conclusion}

DAT is used to detect antibodies (autoantibodies or alloantibodies) and complement on RBCs. A positive DAT result may or may not be associated with hemolysis. The DAT is best interpreted with regard to levels of RBC-bound immunoglobulins and the various clinical situations that can lead to a false-positive result. Clinical conditions that can result in positive DAT include AIHA, drug-induced hemolytic anemia, HDN, investigation of hemolytic transfusion reactions, and PLS. Positive DAT is the diagnostic hallmark of AIHA; however, it may be absent in some cases. DAT is typically positive with anti-IgG antisera in warm AIHA. A patient with CAD shows a positive Coombs' test for anti-C3D and negative for IgG antisera.

Interpretation of the significance of DAT requires knowledge of the patient's diagnosis, drug therapy, recent transfusion, transplantation and pregnancy history, limitations of DAT (sensitivity, specificity), and other laboratory data.

\section{Conflict of interest}

The author had disclosed no conflict of interest.

\section{Disclosure}

The authors declare no conflicts of interest.

\section{References}

1. Kay NE, K. Anderson (1978) Direct antiglobulin "Coombs'" test. Incidence of positive findings in normal population: retrospective study N Y State J Med 78: 1244-1246. [Crossref]

2. Gorst DW, Rawlinson VI, Merry AH, Stratton F (1980) Positive direct antiglobulin test in normal individuals. Vox Sang 38: 99-105. [Crossref]

3. Go RS, Winters JL, Kay NE (2017) How I treat autoimmune hemolytic anemia. Blood 129: 2971-2979. [Crossref]

4. Jeje MO, Blajchman MA, Steeves K, Horsewood P, Kelton JG (1984) Quantitation of red cell-associated IgG using an immunoradiometric assay Transfusion 24:473-476. [Crossref]

5. Gilliland BC, Leddy JP, Vaughan JH (1970) The detection of cell-bound antibody on complement-coated human red cells. J Clin Invest 49: 898-906. [Crossref]

6. Greenwalt TJ, Domino MM, Dumaswala UJ (1992) An enzyme-linked antiglobulin test to quantify nanogram quantities of IgG on polystyrene microspheres, Vox Sang 63: 272-275. [Crossref]

7. Bodensteiner D, Brown P, Skikne B, Plapp F (1983) The enzyme-linked immunosorbent assay: accurate detection of red blood cell antibodies in autoimmune hemolytic anemia, Am J Clin Pathol 79:182-185. [Crossref]

8. Lin JS, Hao TC, Lyou JY, Chen YJ, Liu HM, et al. (2009) Clinical application of a flow cytometric direct antiglobulin test. Transfusion 49: 1335-1346. [Crossref]

9. Frey-Wettstein M, Froelicher S (1992) [Positive direct antiglobulin test (DAGT) using the gel system] Beitr. Infusionsther 30: 378-381. [Crossref]

10. Wang Z, Shi J,Zhou Y, Ruan C (2001) Detection of red blood cell-bound immunoglobulin $\mathrm{G}$ by flow cytometry and its application in the diagnosis of autoimmune hemolytic anemia Int J Hematol 73: 188-193. [Crossref]

11. Hughes-Jones NC, Polley MJ, Telford R, Gardner B, Kleinschmidt G (1964) Optimal conditions for detecting blood group antibodies by the antiglobulin test. Vox Sang 9: 385-395. [Crossref]
12. Dittmar K, Procter JL, Cipolone K, Njoroge JM, Miller J, et al. (2001) Comparison of DATs using traditional tube agglutination to gel column and affinity column procedures. Transfusion 41: 1258-1262. [Crossref]

13. Das SS, Chaudhary R, Khetan D (2007) A comparison of conventional tube test and gel technique in evaluation of direct antiglobulin test. Hematology 12: 175-178. [Crossref]

14. Chaudhary RK, Das SS (2014) Autoimmune hemolytic anemia: From lab to bedside. Asian J Transfus Sci 8: 5-12. [Crossref]

15. Fabijanska-Mitek J, Namirska-Krzton H, Seyfried H (1995) The value of gel test and ELAT in autoimmune haemolytic anaemia. Clin Lab Haematol 17: 311-316. [Crossref]

16. JANDL JH, KAPLAN ME (1960) The destruction of red cells by antibodies in man III. Quantitative factors influencing the patterns of hemolysis in vivo. J Clin Invest 39 1145-1156. [Crossref]

17. G. Garratty, S.J. Nance. Correlation between in vivo hemolysis and the amount of red cell-bound IgG measured by flow cytometry, Transfusion (Paris) 1990; 30:617-621.

18. Fabijańska-Mitek J, Pogłod R, Adamowicz-Salach A, Łopieńska H (2006) Quantitation of red cell-bound IgG by an enzyme-linked antiglobulin test in the patients with warmtype autoimmune haemolytic anaemia. Clin Lab Haematol 28: 241-244. [Crossref]

19. Dubarry M, Charron C, Habibi B, Bretagne Y, Lambin P (1993) Quantitation of immunoglobulin classes and subclasses of autoantibodies bound to red cells in patients with and without hemolysis. Transfusion 33: 466-471. [Crossref]

20. Singh A, Solanki A, Chaudhary R (2014) Demonstration of IgG subclass (IgG1 and IgG3) in patients with positive direct antiglobulin tests Immunohematology 30: 24-27. [Crossref]

21. CONSTANTOULAKIS M, COSTEA N, SCHWARTZ RS, DAMESHEK W (1963) QUANTITATIVE STUDIES OF THE EFFECT OF RED-BLOOD-CELL SENSITIZATION ON IN VIVO HEMOLYSIS. J Clin Invest 42: 1790-1801. [Crossref]

22. Bicakci Z, Ozturkmen S, Akyay A, Olcay L (2012) False positive result of the direct antiglobulin test (DAT): the role of the elevated level of immunoglobulin G. Pediatr Hematol Oncol 29: 611-619. [Crossref]

23. Robertson VM, Dickson LG, Romond EH, Ash RC (1987) Positive antiglobulin tests due to intravenous immunoglobulin in patients who received bone marrow transplant. Transfusion 27: 28-31. [Crossref]

24. Moscow JA, Casper AJ, Kodis C, Fricke WA (1987) Positive direct antiglobulin test results after intravenous immune globulin administration. Transfusion 27: 248-249.

25. Toy PT, Chin CA, Reid ME, Burns MA (1985) Factors associated with positive direct antiglobulin tests in pretransfusion patients: a case-control study. Vox Sang 49: 215 220. [Crossref]

26. Zantek ND, Koepsell SA, Tharp DR Jr, Cohn CS (2012) The direct antiglobulin test a critical step in the evaluation of hemolysis. Am J Hematol 87: 707-709. [Crossref]

27. Huh YO, Liu FJ, Rogge K, Chakrabarty L, Lichtiger B (1988) Positive direct antiglobulin test and high serum immunoglobulin G values, Am J Clin Pathol 90: 197200. [Crossref]

28. Barcellini W (2015) Immune Hemolysis: Diagnosis and Treatment Recommendations, Semin Hematol 52: 304-312. [Crossref]

29. Javed R, Datta SS, Basu S, Chakrapani A (2016) Resolution of Serologic Problems Due to Cold Agglutinins in Chronic Lymphocytic Leukemia Indian J Hematol Blood Transfus 32: 290-293. [Crossref]

30. Petz LD (2004) Review: evaluation of patients with immune hemolysis. Immunohematology 20: 167-176. [Crossref]

31. Gertz MA (2007) Management of cold haemolytic syndrome. Br J Haematol 138: 422 429. [Crossref]

32. Bass GF, Tuscano ET, Tuscano JM (2014) Tuscano. Diagnosis and classification of autoimmune hemolytic anemia. Autoimmun Rev 13:560-564. [Crossref]

33. Lechner K, Jäger U (2010) How I treat autoimmune hemolytic anemias in adults. Blood 116: 1831-1838. [Crossref]

34. Rottenberg Y, Yahalom V, Shinar E, Barchana M, Adler B, et al. (2009) Blood donors with positive direct antiglobulin tests are at increased risk for cancer. Transfusion 49: 838-842. [Crossref]

35. Thedsawad A, Taka O, Wanachiwanawin W (2011) Development of flow cytometry for detection and quantitation of red cell bound immunoglobulin $\mathrm{G}$ in autoimmune hemolytic anemia with negative direct Coombs test. Asian Pac J Allergy Immunol 29 : 364-367. [Crossref] 
36. Segel GB, Lichtman MA (2014) Direct antiglobulin ("Coombs") test-negative autoimmune hemolytic anemia: a review. Blood Cells Mol Dis 52: 152-160. [Crossref]

37. Kamesaki T, Kajii E (2018) A Comprehensive Diagnostic Algorithm for Direct Antiglobulin Test-Negative Autoimmune Hemolytic Anemia Reveals the Relative Ratio of Three Mechanisms in a Single Laboratory. Acta Haematol 140: 10-17. [Crossref]

38. Parker V, Tormey CA (2017) The Direct Antiglobulin Test: Indications, Interpretation, and Pitfalls. Arch Pathol Lab Med 141: 305-310. [Crossref]

39. Takahashi T (2018) Direct Antiglobulin Test-Negative Autoimmune Hemolytic Anemia. Acta Haematol 140: 18-19.

40. Merry AH, Thomson EE, Rawlinson VI, Stratton F (1984) Quantitation of IgG on Erythrocytes: correlation of number of IgG molecules per cell with the strength of the direct and indirect antiglobulin tests. Vox Sang 47: 73-81. [Crossref]

41. Gilliland BC (1976) Coombs--negative immune hemolytic anemia. Semin Hematol 13: 267-275. [Crossref]

42. Arndt PA, Garratty G (2005) The changing spectrum of drug-induced immune hemolytic anemia. Semin Hematol 42: 137-144. [Crossref]

43. Worlledge SM, Carstairs KC, Dacie JV (1966) Autoimmune haemolytic anaemia associated with alpha-methyldopa therapy. Lancet 2: 135-139. [Crossref]

44. Petz LD, Fudenberg HH (1966) Coombs-positive hemolytic anemia caused by penicillin administration. N Engl J Med 274: 171-178. [Crossref]

45. Arndt PA, Leger RM, Garratty G (2012) Serologic characteristics of ceftriaxone antibodies in 25 patients with drug-induced immune hemolytic anemia. Transfusion 52: 602-612. [Crossref]

46. Leger RM, Arndt PA, Garratty G (2014) How we investigate drug-induced immune hemolytic anemia. Immunohematology 30: 85-94. [Crossref]

47. Bakkeheim E1, Bergerud U, Schmidt-Melbye AC, Akkök CA, Liestøl K, et al. (2009) Maternal IgG anti-A and anti-B titres predict outcome in ABO-incompatibility in the neonate. Acta Paediatr 98: 1896-1901. [Crossref]
48. Fasano RM (2016) Hemolytic disease of the fetus and newborn in the molecular era. Semin Fetal Neonatal Med 21: 28-34. [Crossref]

49. Ness PM, Shirey RS, Thoman SK, Buck SA (1990) The differentiation of delayed serologic and delayed hemolytic transfusion reactions: incidence, long-term serologic findings, and clinical significance, Transfusion 30: 688-693. [Crossref]

50. ElAnsary M, Hanna MO, Saadi G, ElShazly M, Fadel FI, et al. (2015) Passenger lymphocyte syndrome in $\mathrm{ABO}$ and Rhesus $\mathrm{D}$ minor mismatched liver and kidney transplantation: A prospective analysis. Hum Immunol 76: 447-452. [Crossref]

51. Cserti-Gazdewich CM, Waddell TK, Singer LG, Chaparro C, Pendergrast JM, et al (2009) Passenger lymphocyte syndrome with or without immune hemolytic anemia in all Rh-positive recipients of lungs from rhesus alloimmunized donors: three new cases and a review of the literature. Transfus Med Rev 23: 134-145. [Crossref]

52. Judd WJ, Barnes BA, Steiner EA, Oberman HA, Averill DB, et al. (1986) The evaluation of a positive direct antiglobulin test (autocontrol) in pretransfusion testing revisited. Transfusion 26: 220-224. [Crossref]

53. Juraković-Loncar N, Hundrić-Haspl Z, Balija M, Grgicević D (1995) [Evaluation of the direct antiglobulin test] Lijec. Vjesn 117: 274-277. [Crossref]

54. Stec N, Shirey RS, Smith B, Kickler TS, Ness PM (1986) The efficacy of performing red cell elution studies in the pretransfusion testing of patients with positive direct antiglobulin tests, Transfusion 26: 225-226. [Crossref]

55. Petz LD (2004) A physician's guide to transfusion in autoimmune haemolytic anaemia. Br J Haematol 124: 712-716. [Crossref]

56. Drouillard DD (2008) Transfusion therapy for autoimmune hemolytic anemia patients: a laboratory perspective. Clin Lab Sci 21:7-11. [Crossref]

57. Shirey RS, Boyd JS, Parwani AV, Tanz WS, Ness PM, et al. (2002) Prophylactic antigen-matched donor blood for patients with warm autoantibodies: an algorithm for transfusion management. Transfusion 42: 1435-1441. [Crossref]

58. El Kenz H, Efira A, Le PQ, Thiry C, Valsamis J, et al. (2014) Transfusion support of autoimmune hemolytic anemia: how could the blood group genotyping help? Transl Res 163: 36-42. [Crossref]

Copyright: (C2018 Lin J. This is an open-access article distributed under the terms of the Creative Commons Attribution License, which permits unrestricted use, distribution, and reproduction in any medium, provided the original author and source are credited. 